\title{
Study on the Hydraulic Parameters of Woshaxi Landslide Soils during Water Level Drawdown of Three Gorges Reservoir
}

\author{
Zhenhua Zhang $\mathbb{D}^{1,2}$ Xiaoyu Huang, ${ }^{1}$ Wu Liu $\mathbb{D}^{1,2}$ and Liang Wang ${ }^{1}$ \\ ${ }^{1}$ School of Civil Engineering, Hefei University of Technology, Anhui Province, Hefei 230009, China \\ ${ }^{2}$ Key Laboratory of Geological Hazards on Three Gorges Reservoir Area (China Three Gorges University), Ministry of Education, \\ Hubei Province, Yichang 443002, China
}

Correspondence should be addressed to Wu Liu; liuwu168@hfut.edu.cn

Received 27 August 2019; Revised 18 December 2019; Accepted 30 December 2019; Published 13 January 2020

Academic Editor: Zhenjiang You

Copyright ( 2020 Zhenhua Zhang et al. This is an open access article distributed under the Creative Commons Attribution License, which permits unrestricted use, distribution, and reproduction in any medium, provided the original work is properly cited.

\begin{abstract}
Variation of hydraulic parameters for unsaturated soil in bank slopes during reservoir water rising or falling process is crucial to scientific analysis and evaluation of bank slope stability. In this paper, soil samples from the Woshaxi landslide in the Three Gorges Reservoir were taken for a permeability test under reservoir drawdown conditions using an independently developed apparatus, which can simulate the variation process of internal seepage in bank slope soils. Changes of particle gradations, soil-water characteristic curves, and unsaturated permeability functions of the soil samples during reservoir falling process were studied by combining with the physical empirical model and numerical simulation. Permeability test results show that fine particles in soil samples migrated and were lost under seepage force action during the tests, leading to a continuous decrease of fine particle content indicated in the grain size distribution curves, in which particles with a size less than $0.02 \mathrm{~mm}$ lose the most. As permeation time increases, the soil saturated permeability enhances constantly with the change rate increasing first and then decreasing. The soil-water characteristic curves change obviously in the high matrix suction section $\left(10 \sim 10^{4} \mathrm{kPa}\right)$, and the volumetric water content decreases constantly and shows a positive correlation with the fine particle content. During the permeability test, the unsaturated permeability coefficient corresponding to a fixed matric suction increases with the drawdowns of the reservoir water level. Slope stability results show that neglecting the variational characteristics of hydraulic parameters in slope stability evaluation can result in a bigger safety factor, which is dangerous for slope safety evaluation. The research results can provide a scientific basis for the stability analysis and evaluation of the bank slopes in the Three Gorges Reservoir Area.
\end{abstract}

\section{Introduction}

Landslides in the reservoir area, as a common natural hazard, are prone to being triggered by water level fluctuations. After the impoundment of the Three Gorges Reservoir, water level changes during reservoir operation have brought an adverse impact on the stabilities of numerous bank slopes [1-3]. To be specific, the periodic rise and fall of reservoir water level changes the seepage field inside the bank slope, and the long-term immersion can lead to variations of the physical and mechanical properties of slope soils during reservoir operation, which would then affect the stability of the bank slope and result in the reactivation of ancient landslides and the occurrence of new landslides [4-6]. Statistics shows that about 4600 landslides had occurred in bank slopes before the impoundment of Three Gorges Reservoir, in which approximately $42.7 \%$ occurred with the leading edge below the normal reservoir water level of $175 \mathrm{~m}$ [7]. As bank slope soils in the drawdown area is in a cyclic saturated and unsaturated state during reservoir operation, the slope stability should be studied based on the seepage field calculated with unsaturated seepage methods. Before the analysis of unsaturated seepage flow, relevant hydraulic parameters of unsaturated soil should be determined firstly, such as soil-water characteristic curve and hydraulic conductivity function. The accuracy 
of these hydraulic parameters is the key to scientifically analyzing and evaluating the stability of the bank slope in the reservoir area [8-11]. Therefore, it is particularly significant to effectively determine the hydraulic parameters of unsaturated soils in the bank slope during reservoir operation.

In recent years, a lot of researches have been done related to the determination of hydraulic parameters of unsaturated soil on the bank slope. Through in-situ tests, Jian et al. [12] had measured the real-time variation of moisture content and matrix suction for the topsoil on the loess landslide in the Three Gorges Reservoir, and well fitted the hydraulic conductivity function under unsaturated conditions with the Van Genuchten model. Wei et al. [13] had evaluated the soil-water characteristic curve of the gravelly soil layer of the sliding mass of the Xietan landslide using a double-ring technique and indicated that the saturation permeability coefficient was closely related to material porosity and particle size distribution. Wayllace et al. [14] proposed the transient water release and imbibition method to determine the soil-water characteristic curves and hydraulic conductivity functions, which could effectively determine the unsaturated hydraulic parameters of different types of soil mass in the unsaturated state by combining with a physical test and numerical simulation. After studying and analyzing the particle fractal characteristics and soil-water characteristic curves of the sliding zone soil and surface soil, Zuo et al. [15] proposed the method of combining particle size fractal dimension with the Brooks-Corey model to predict the soil-water characteristic curves, with the predicted results in good consistency with the measured soil-water characteristic curves.

Although previous researches have provided significant contribution to the knowledge of the hydraulic parameters of unsaturated soils in bank slopes, most studies basically assumed that the physical properties and hydraulic parameters of the slope soils did not change when the reservoir water rose or fell, without considering the influence of reservoir water fluctuations on the particle distribution and permeability characteristics of bank slope soils during the actual reservoir operations. Existing studies have found that soils are prone to seepage erosion under the action of osmotic force [16]. The migration and loss of fine particles during seepage erosion will change the soil particle degradation and result in the variation of pore structure, which directly affects the soil's hydraulic parameters [17-19]. Thus, in order to obtain real and objective hydraulic parameters of slope soils, it is necessary to consider the dynamic characteristics of soil hydraulic parameters in the course of reservoir water rise or fall. In the light of that, in this study, a novel seepage device was independently developed to simulate the dynamic seepage process inside the soil of a bank slope. Grain size distributions, soil-water characteristic curves, and hydraulic conductivity functions of the sliding soil from the Woshaxi landslide in the Three Gorges Reservoir during the falling processes of reservoir water level were studied for obtaining more accurate hydraulic parameters to analyze the bank slope stability.

\section{Experimental Study}

2.1. Experimental Setup. Owing to the variation of the seepage field in a bank slope when subjected to reservoir water fluctuations, the position of the phreatic line, the values of the hydraulic head and gradient, and the seepage direction of the soil mass below the phreatic line vary constantly, which makes it difficult to effectively determine the soil hydraulic parameters during reservoir operations with conventional seepage test equipment. To make an improvement, a new permeation apparatus shown in Figures 1 and 2 was developed to truly simulate the variation process of a seepage field inside the bank slope soil. By constantly adjusting the inclination angle of the sample holder and values of the tested water head to simulate the changes in seepage direction and hydraulic gradient in the soil mass, respectively, the apparatus can dynamically simulate the seepage field of a soil mass at a certain position in the bank slope during the fluctuations of reservoir water level and measure the hydraulic parameters in the dynamic process.

The permeation apparatus is composed of the permeameter unit, the water supply unit, and the water collecting unit (see Figure 1). The permeameter unit mainly consists of a sample holder, a rotating support, and a fixing support (see Figure 2). In order to facilitate the observation of experimental phenomena during the test, the sample holder is comprised of a transparent plexiglass pipe, with the internal diameter being no less than 5 times that of the characteristic particle size $d_{85}$ and the length being 2 3 times that of the internal diameter [20]. The sample holder is divided by the upper and lower porous plates into the water-entry buffer section, the sample section, and the water-exit section, in which the water-entry buffer section is filled with gravels for the purpose of the water-entry buffer and uniform infiltration. The tested soil sample is placed in the middle of the sample holder and separated with the porous plate by a gauze net. Gaps between the porous plate and the pipe wall are sealed with waterproof plasticine to prevent the loss of large soil particles. The supporting tube in the water-exit section is a transparent plexiglass pipe with permeable holes on the wall to facilitate the observation of the seepage flow.

A rotating support is installed on a fastening bolt outside of the sample container and fixed in the middle position of the fastening bolt through the nut. Both ends of the rotating support are placed in the slot of the fixed vertical bracket plate. By controlling the rotation of the rotating support, the inclination angle of the sample holder can be adjusted to simulate the dynamic change of seepage direction in the sample.

The water supply unit is composed of a water tank, a water pump, and a water supply bucket. An overflow pipe is installed on the side wall of the water supply bucket to ensure a constant water head and achieve the function of water recycling. The water collecting unit contains a water collecting bucket and a measuring cylinder, in which the measuring cylinder collects water that overflowed from the hole on the side wall of the water collecting bucket. During the test, the water head on both sides of the sample can be dynamically set by adjusting the height of the water supply bucket and the collecting bucket. 


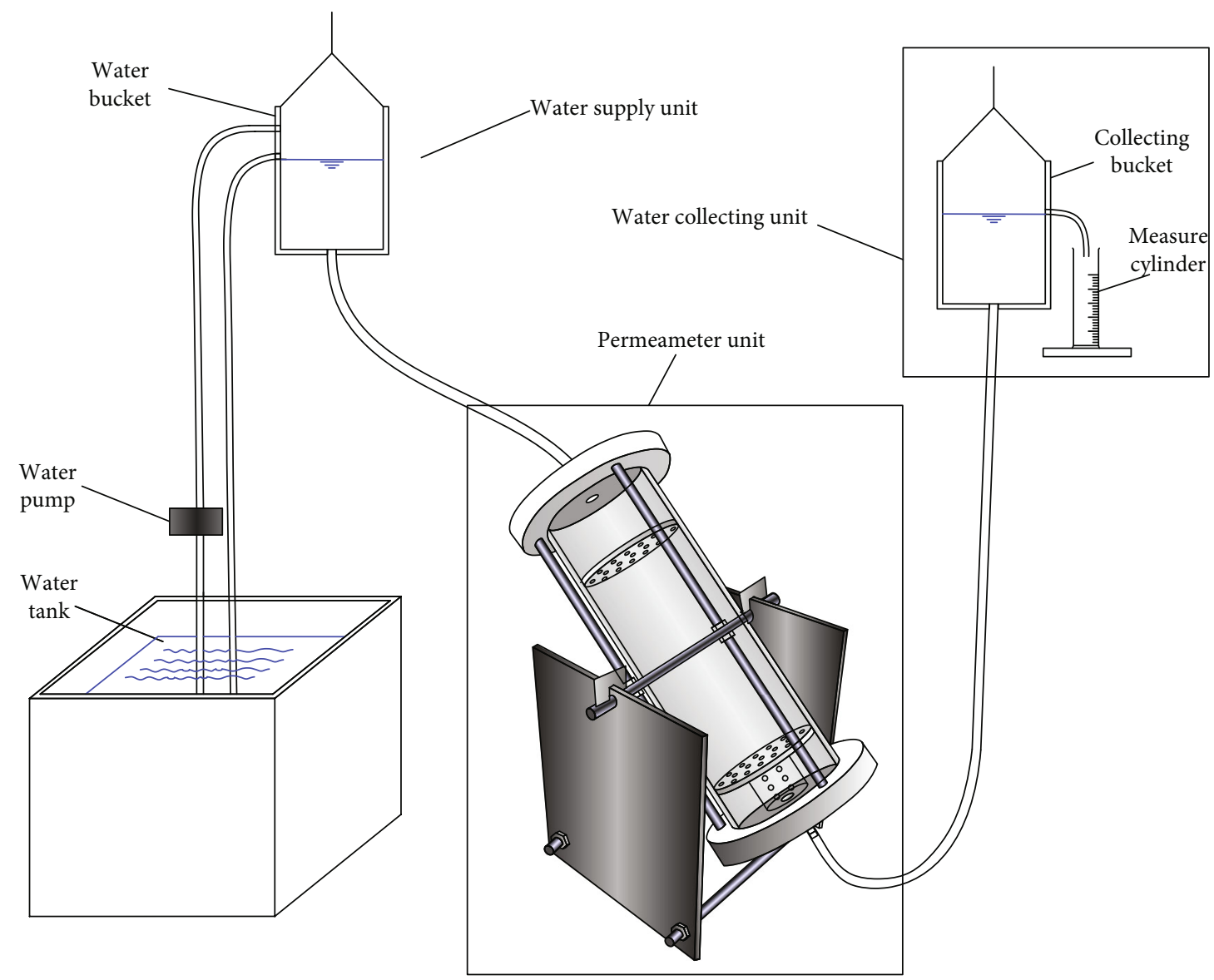

FIGURE 1: Overall schematic diagram of permeation apparatus.

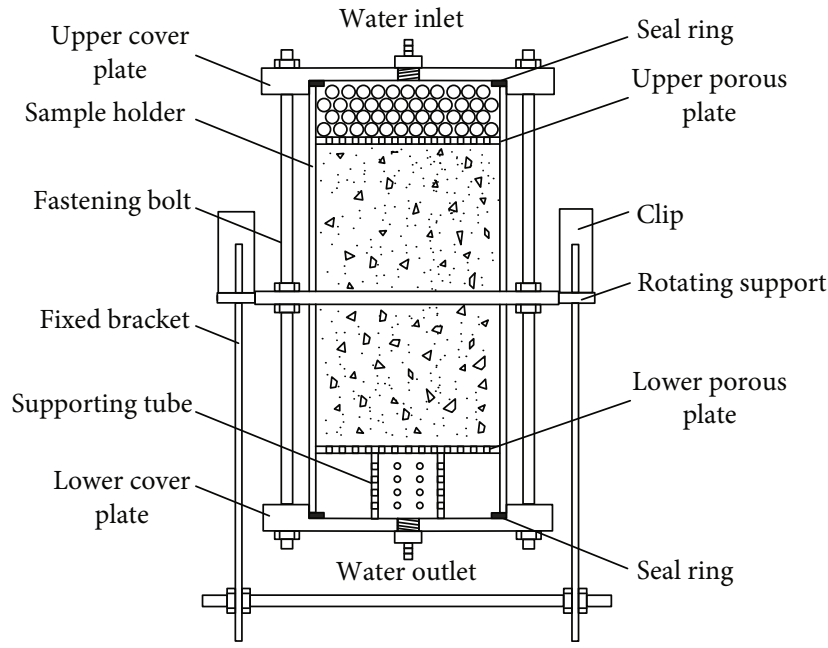

(a) Structure diagram

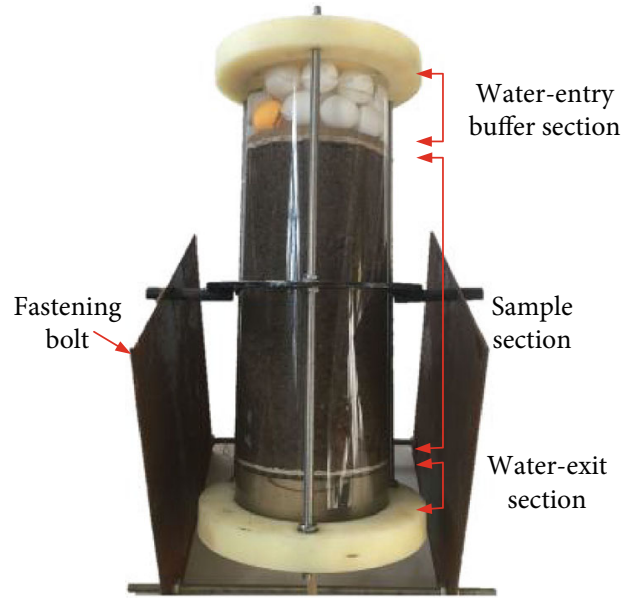

(b) Device objects

Figure 2: Details of the permeameter.

\subsection{Method for Unsaturated Hydraulic Parameter Determination}

2.2.1. Soil-Water Characteristic Curve Determination. Due to the disadvantages of long time and high cost in measuring a soil-water characteristic curve by conventional test methods (pressure plate extractor or Tempe plate), the effective physical empirical model proposed by Kong and Song [21] based on 406 sets of measured data is used in this paper to rapidly and effectively obtain the soil-water characteristic curve. 


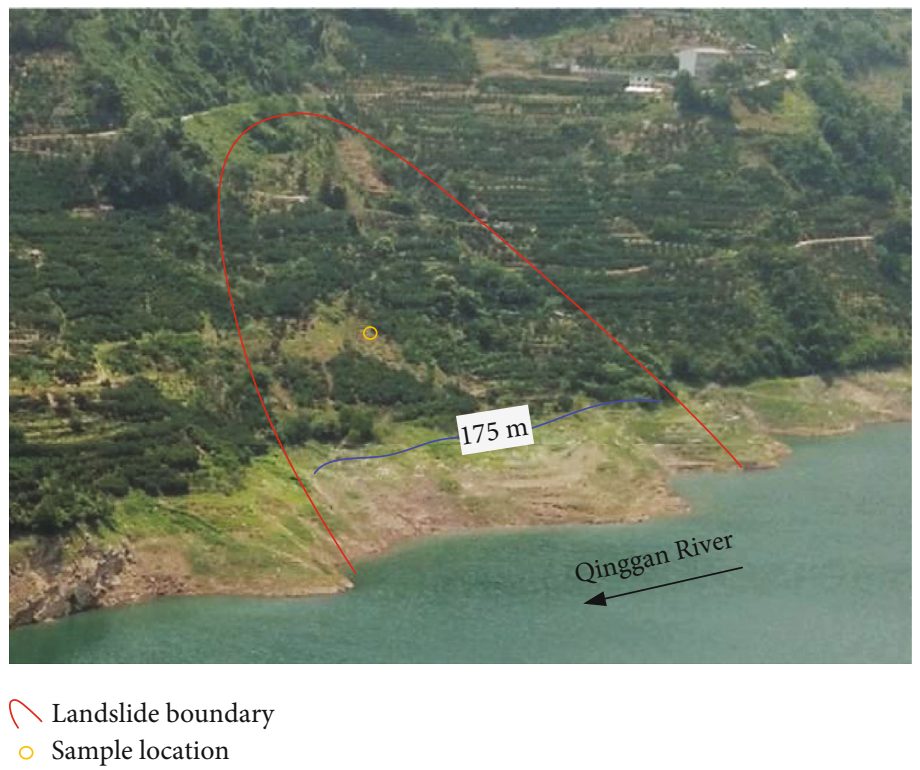

Figure 3: The sampling site of soil samples in the Woshaxi landslide.

Specifically, the soil-water characteristic curve can approximately be determined according to the particle distribution curve of the soil sample using the following formula:

$$
\begin{gathered}
S=P(d), \\
d=\frac{6 \sigma R_{\mathrm{ou}}}{[(1+e) \Psi]}, \\
\ln R_{\mathrm{ou}}=a \ln \left(\frac{\Psi}{\gamma_{\mathrm{w}}}\right)+b,
\end{gathered}
$$

where $S$ is the degree of water saturation; $P(d)$ is the particle size distribution function; $d$ is the particle size; $\sigma$ is the surface tension coefficient of water; $\gamma_{\mathrm{w}}$ is the unit weight of water; $e$ is the void ratio; $R_{o u}$ is the correction factor; $\Psi$ is the matric suction; and $a$ and $b$ are fitting parameters.

When using the physical empirical model to predict the soil-water characteristic curve of the tested soil sample, the following steps are included:

(1) Determine the void ratio $e$ and particle size distribution function $P(d)$

(2) Assume a value of the matric suction $\Psi$ and calculate the corresponding water saturation $S$ using equation (3), equation (2), and equation (1) in sequence

(3) Calculate the value of $S$ corresponding to a different value of $\Psi$ by repeating step (2). Obtain the corresponding relation between volumetric water content and matric suction by converting saturation $S$ into volumetric water content, that is, the soil-water characteristic curve

Considering that the sliding soil mass of the Woshaxi landslide in this study is relatively similar to that of the Xitan landslide, the fitting parameters $a$ and $b$ in this paper are back-calculated from the existing tested data on Xitan sliding soils [13]: $a=-0.5932$ and $b=3.3819$ for $\Psi<50 \mathrm{kPa}$ and $a=0.6228$ and $b=1.5869$ for $\Psi>50 \mathrm{kPa}$.

2.2.2. Hydraulic Conductivity Function Determination. At present, methods to determine the hydraulic conductivity function are mainly divided into two categories: direct test method and indirect prediction method based on an established function model. The latter method is widely used in practice because of its convenience and effectivity [22-25]. Functional models widely used in geotechnical engineering are the Fredlund-Xing model [26] and the van Genuchten model [27]. Both can predict the hydraulic conductivity function through a soil-water characteristic curve and saturated hydraulic conductivity. In this paper, the FredlundXing function model, built in the Seep/W module of the Geo-studio software, is used to determine the hydraulic conductivity function of a tested soil sample by inputting the calculated soil-water characteristic curve and measured saturated hydraulic conductivity.

2.3. Test Sample. The soils tested in this paper were taken from the sliding mass above an elevation of $175 \mathrm{~m}$ in the Woshaxi landslide in the Three Gorges Reservoir (see Figure 3), where the soils were scarcely affected by the fluctuation of the reservoir water level. They can objectively reflect the physical and mechanical characteristics of the soil before reservoir impoundment. Physical parameters and the grainsize distribution curve of the tested soil shown in Table 1 and Figure 4 indicate that the tested soil belongs to coarse granular soil. As the nonuniformity coefficient $C_{\mathrm{u}}>5$ and curvature coefficient $C_{\mathrm{c}}<1$, the soil sample is poorly graded with nonuniform distribution.

The soil content of the tested sample is $54.3 \%$ if $2 \mathrm{~mm}$ is taken as the dividing particle size of soil and rock parts 
TABle 1: Physical parameters of soil samples.

\begin{tabular}{lcccccc}
\hline Property & Natural water content $(\%)$ & Natural density $\left(\mathrm{g} / \mathrm{cm}^{3}\right)$ & Void ratio & Dry density $\left(\mathrm{g} / \mathrm{cm}^{-3}\right)$ & $C_{\mathrm{u}}$ & $C_{\mathrm{c}}$ \\
\hline Value & 13.1 & 1.6 & 0.65 & 1.6 & 1222 & 0.065 \\
\hline
\end{tabular}

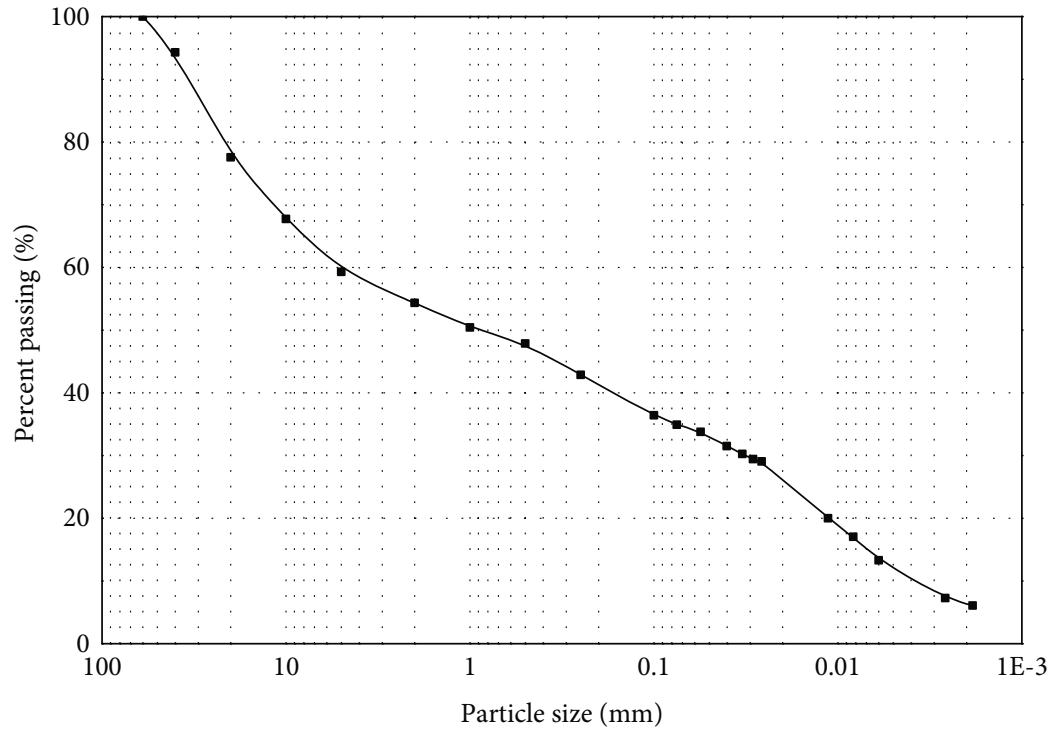

FIGURE 4: Grain-size distribution curve of soil samples.

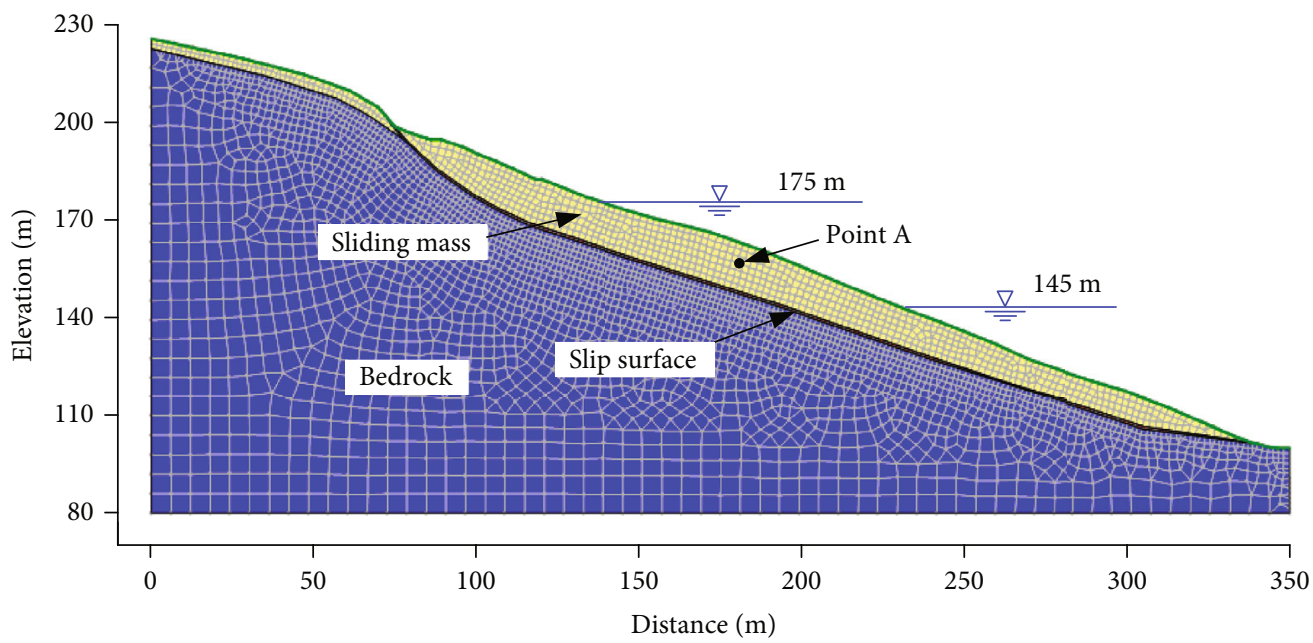

Figure 5: Numerical seepage analysis model of the Woshaxi landside.

[28]. As the water content of the soil is high, $13.1 \%$ in natural water content, soil particles are prone to be consolidated into blocks or aggregates formed by soils and rocks. Generally, due to the small size of the sample holder, the insitu selected soils were remolded in the laboratory and then used as tested samples.

2.4. Test Procedure. In order to study the variation law of a grain-size distribution curve, a soil-water characteristic curve, and an unsaturated hydraulic conductivity function of unsaturated soil of the sliding mass in the Woshaxi landslide during the reservoir water drawdown process, the independently developed apparatus introduced in Section 2.1 is used to simulate the seepage process at point A (see Figure 5) in the sliding mass of the Woshaxi landslide. The grain-size distribution curves and soil-water characteristic curves of the soil mass at point A in the reservoir water drawdown course are tested and evaluated through a combination 


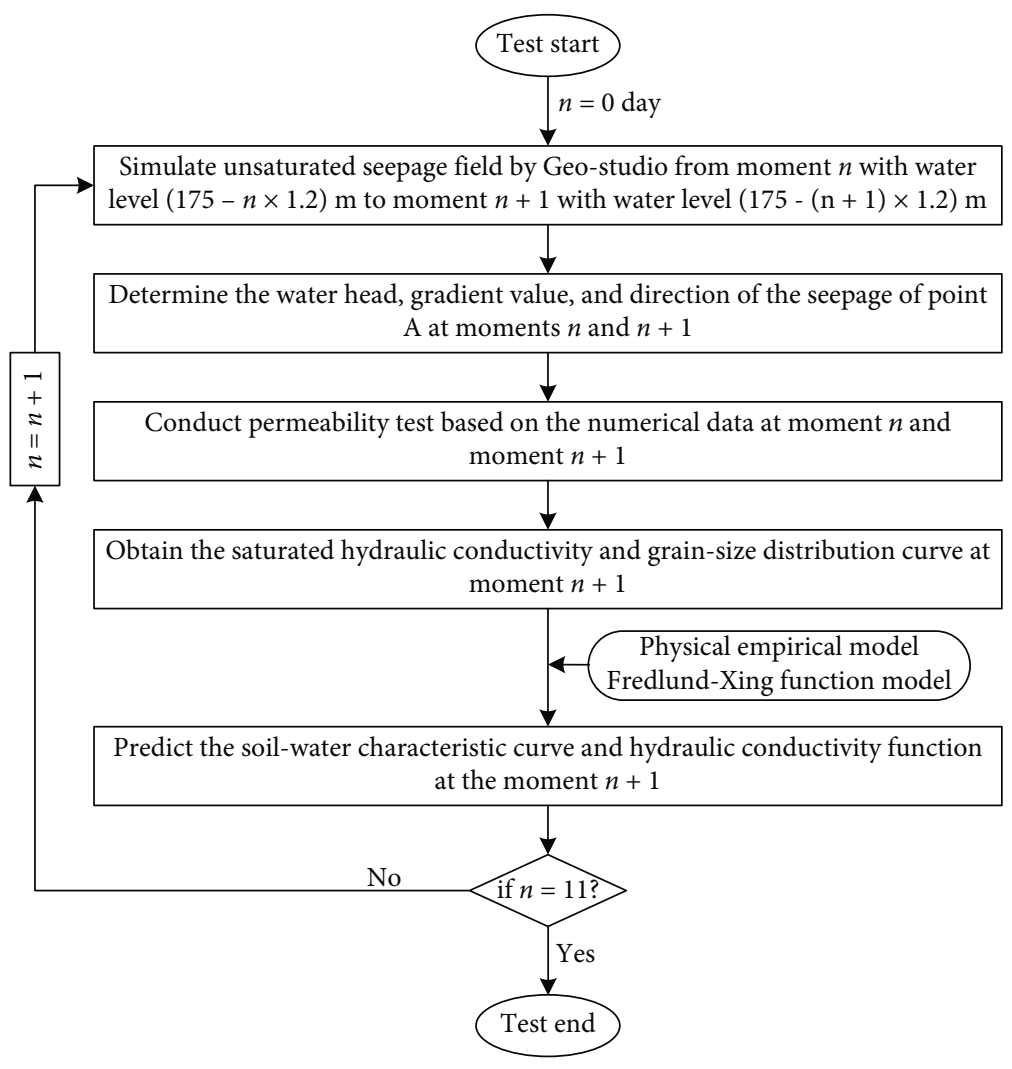

Figure 6: Flow chart of the test procedure.

of permeability tests and numerical simulations. The specific procedure for the tests and evaluations is described below, with the flow chart shown in Figure 6.

(1) Firstly, assume the first moment $n=0$ day (initial time) and evaluate the soil-water characteristic curve and hydraulic conductivity function of the initial soil sample with the method mentioned in Section 2.2. Divide the soil samples for stratified sample loading, with $2 \sim 3 \mathrm{~cm}$ in thickness for each layer. To ensure that the particle size distribution of each layer is consistent with that of the whole, gentle compaction with a wooden hammer was conducted on each layer to achieve the required dry density of the sliding soil. After sample loading, the water supply bucket slowly supplied water to fill the permeameter from bottom to top until the air in the whole device was discharged

(2) Calculate the unsaturated seepage field based on the numerical model established through the Seep/W module of the Geo-studio software (see Figure 5) under the condition where the reservoir water level falls from moment $n$ with a water level of elevation $(175-n \times 1.2) \mathrm{m}$ to moment $n+1$ with a water level of $(175-(n+1) \times 1.2) \mathrm{m}$ at a velocity of $1.2 \mathrm{~m} / \mathrm{d}$ [29]. Record the water head, gradient value, and direction of the seepage of point $\mathrm{A}$ at moments $n$ and $n+1$, in which the seepage direction is determined by gradient components in the horizontal and vertical directions
(3) Conduct a seepage test based on the recorded results from step (2). During the test, the water head and seepage angle of the test sample are dynamically adjusted according to the numerical data at moment $n$ and moment $n+1$ to simulate the change process of the seepage field at point A during this period. Specific steps of the permeability test are shown as follows:

(a) Take the water head at moment $n$ obtained in step (2) as the inlet water head of the tested sample, while the outlet water head is determined according to the head loss calculated by the gradient value $J$ at point A and the total length $L$ of the sample, that is, $H_{\text {outlet }}=H_{\text {inlet }}-J \times L$. Similarly, the water head and inclination angle of the tested sample at moment $n+1$ can be determined

(b) Since the variation of the water head and inclination angle from moment $n$ to moment $n+1$ is continuous and gradual, the time interval (24 hours) is divided evenly into three time periods during the test. The water head and inclination angle are adjusted every 8 hours

(c) Measure the saturated hydraulic conductivity of the tested sample at moment $n+1$. Carry out a sieve test on the tested soils taken from the outlet end with $1.5 \sim 2 \mathrm{~cm}$ in thickness to determine the grain-size distribution curve after $n+1$ days' 


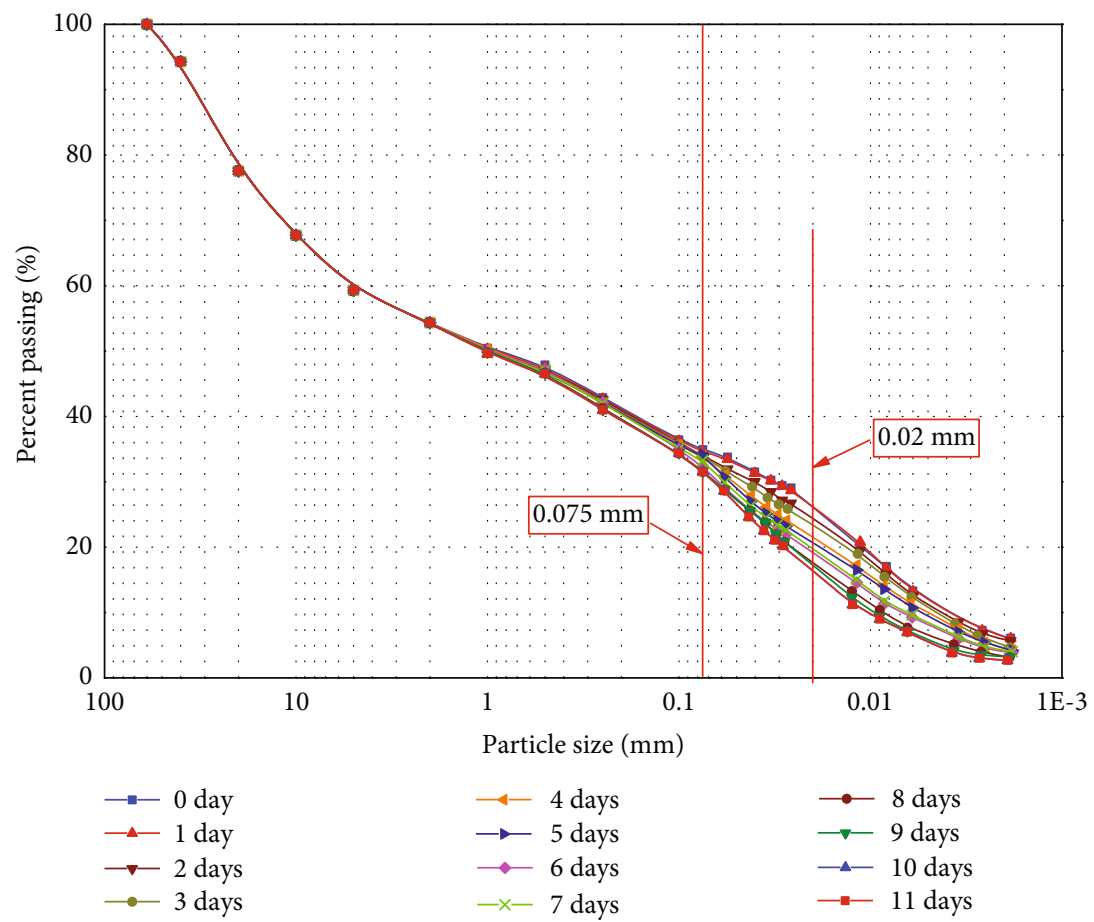

Figure 7: Grain-size distribution curves of tested samples after different days of permeation.

permeability test. The remaining soil sample in the device will be used to continue further permeability tests

(4) Predict the soil-water characteristic curve and hydraulic conductivity function at moment $n+1$ based on the obtained saturated hydraulic conductivity and grain-size distribution curve in step (3c)

(5) According to the unsaturated hydraulic parameters at moment $n+1$, let $n=n+1$. Repeat steps (2) to (4) to dynamically determine the grain-size distribution curves, saturated hydraulic conductivities, and hydraulic conductivity functions of the sliding soil at point $\mathrm{A}$ at different moments during the reservoir water falling process

(6) The test ended when the process of reservoir water level drawdown was set to be finished (the total time of the process is 11 days)

\section{Test Results and Analysis}

3.1. Grain-Size Distribution Results. By dynamically adjusting the water head and seepage angle of the sample in the permeability test to simulate the seepage process in the sliding body under a reservoir water falling condition, sieve analysis of the soil sample at the end of each day during the test was performed. As the soil particles with a size larger than $2 \mathrm{~mm}$ usually lose less in the permeation process [30], and a $2 \mathrm{~mm}$ aperture gauze was placed between the bottom permeable plate and the soil sample, the content of soil particles larger than $2 \mathrm{~mm}$ is considered basically unchanged. The grain-size distribution curves of the tested sample at the end of each day were plotted from the sieve test result and shown in Figure 7.

It can be seen from Figure 7 that the percent passing of the soil sample with a size less than $2 \mathrm{~mm}$ generally decreases with the increase of permeability test days under the reservoir water falling condition, in which the content with particles larger than $0.075 \mathrm{~mm}$ shows relatively small changes, while particles smaller than $0.075 \mathrm{~mm}$ show a relatively obvious change. During the whole test, the mass percentage of soil particles with a size less than $0.075 \mathrm{~mm}$ decreases from $34.9 \%$ to $31.5 \%$ with a reduction ratio of $9.7 \%$. Among these particles, those with sizes less than $0.02 \mathrm{~mm}$ decrease significantly from $26.4 \%$ to $16.3 \%$ with a reduction ratio of $38.3 \%$.

In order to show a more intuitional change of fine grain content in the soils at point $\mathrm{A}$, the particle contents with diameters $d<0.075 \mathrm{~mm}$ and $d<0.02 \mathrm{~mm}$ were selected and depicted in Figure 8 for analysis. Figure 8 shows that the mass percentages of soil particles with sizes $d<0.075$ $\mathrm{mm}$ and $d<0.02 \mathrm{~mm}$ decrease gradually with the increasing number of permeability test days; the mass percentage decrease rates are $0.34 \% /$ day and $0.99 \%$ /day, respectively. It can be seen that the soil samples are prone to seepage erosion due to the action of the seepage force during the reservoir water falling process, resulting in the gradual migration and loss of fine grains. Furthermore, the loss rate of soil particles with sizes less than $0.02 \mathrm{~mm}$ are larger than those with sizes less than $0.075 \mathrm{~mm}$, indicating that the mass percentage of soil particles with smaller sizes deceases relatively faster.

3.2. Saturated Hydraulic Conductivity Results. Figure 9 shows the measured saturated hydraulic conductivities of the soil sample in the sliding mass at different times. The saturated hydraulic conductivity of the tested soil sample increases 


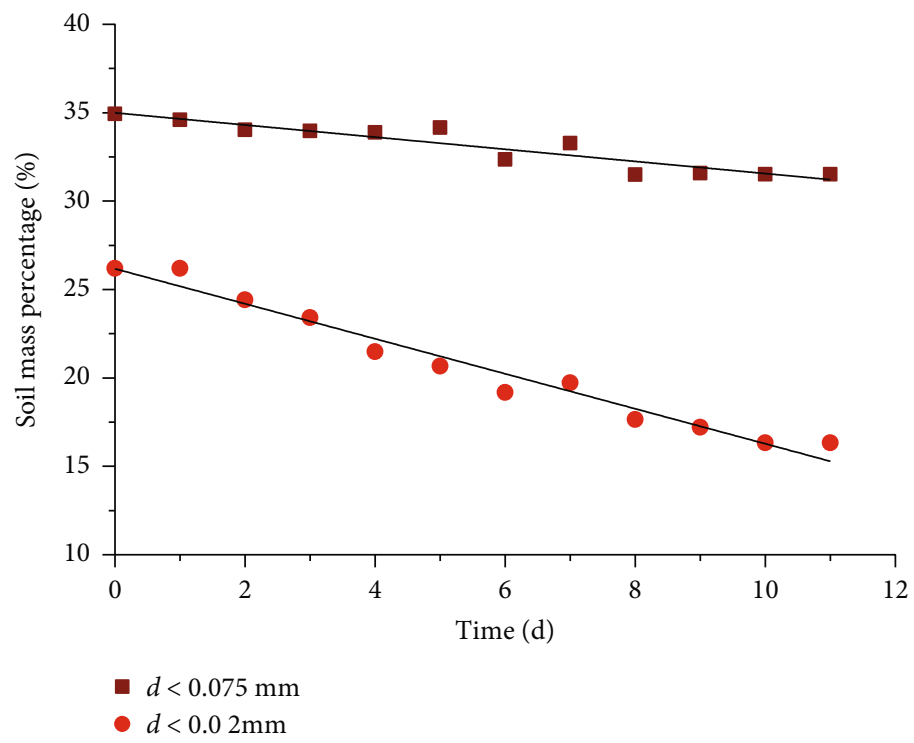

Figure 8: Variations of soil particles with different sizes during the test.

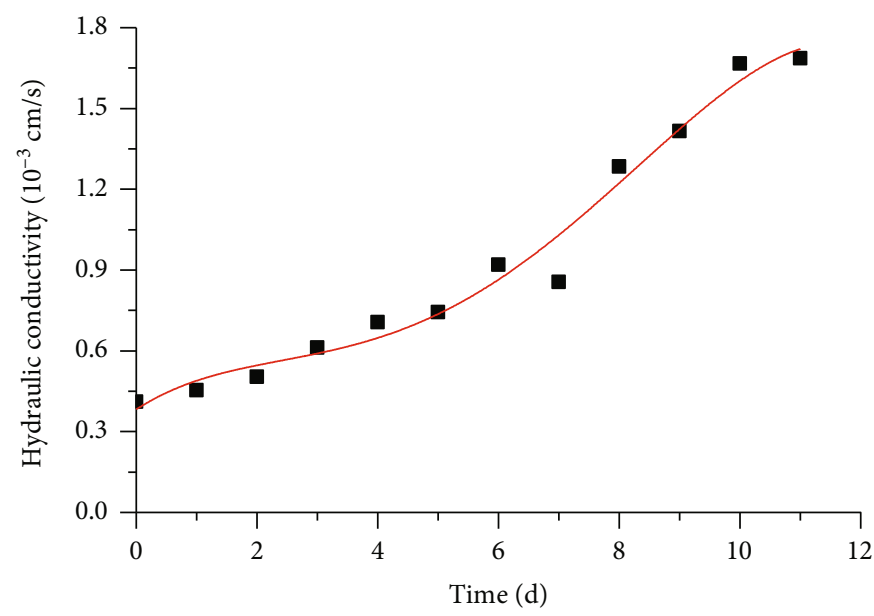

FIgURE 9: Variations of saturated hydraulic conductivity with time.

gradually during the permeability test. At the beginning, the saturated hydraulic conductivity increases slightly. As the number of the permeation days increases, the change rate of saturated hydraulic conductivity increases first and then decreases. Since the saturated hydraulic conductivity is within the range of $10^{-4} \sim 10^{-2} \mathrm{~cm} / \mathrm{s}$, the tested sample belongs to medium permeable soil. As a coarse-grain soil, the coarse particles in the soil sample serve as the skeleton, while the fine particles fill the pores formed by the skeleton. In the initial reservoir water level falling stage, due to less migration and loss of fine particles and variation of pore structure (see Figure 10), the saturated hydraulic conductivity increases gradually but with small amplitude. With the continuous loss of fine particles and gradual formation of seepage channels (see Figure 10), the increase rate of saturated hydraulic conductivity enhances. When the formed seepage channels basically keep stable in the later stage of the test, the increase rate decreases. Thus, the saturated hydraulic conductivity of the soil mass in the sliding mass changes constantly during reservoir water drawdown process.

3.3. Soil-Water Characteristic Curve Results. According to the measured saturated hydraulic conductivities and grain-size distribution results of the soil sample at different moments, the soil-water characteristic curves during the reservoir water falling process are determined with equations (1)-(3) and shown in Figure 11.

The plotted soil-water characteristic curve (see Figure 11) demonstrates that with the increase of matric suction, the volumetric moisture content changes slightly at the initial stage, and then drops sharply to a certain level in the intermediate stage. After that, the variation of the volumetric moisture content is small even if the matrix suction increases by several orders of magnitude. By comparing the soil-water 


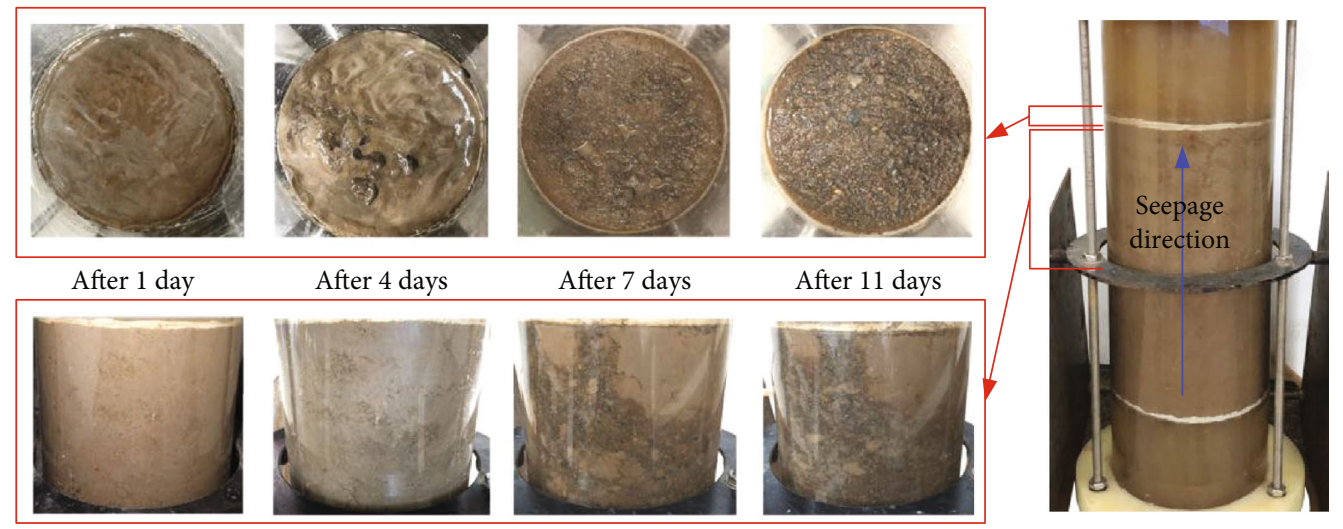

Figure 10: Progression of seepage erosion of the soil samples during the permeability test.

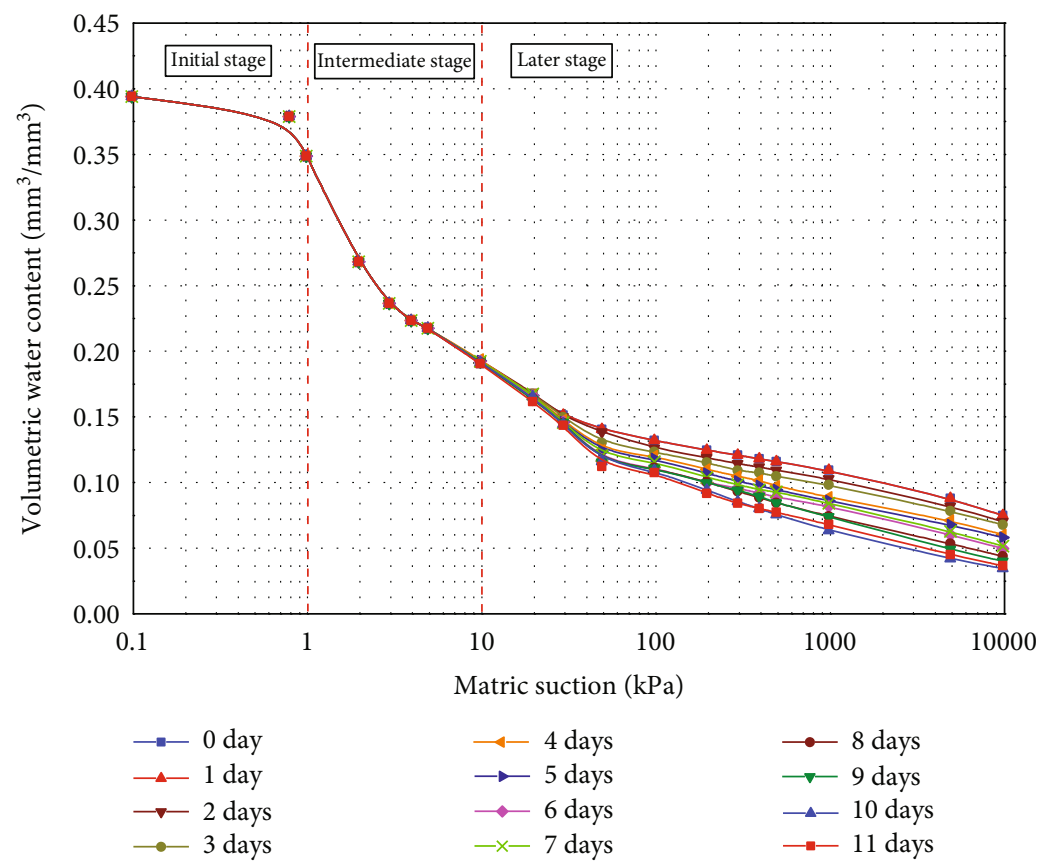

FIGURE 11: Soil water characteristic curves of soil samples after different days of permeation.

characteristic curves at different moments, one can find that these curves are basically the same at low matric suction stage $(0.1 \sim 10 \mathrm{kPa})$, but differences between these curves are obvious at high matric suction stage $\left(10 \sim 10^{4} \mathrm{kPa}\right)$. The volumetric water content tends to decrease gradually with the increase of permeability test times under the same matric suction condition. At matric suction of $10^{4} \mathrm{kPa}$, the residual volumetric water content decreases generally with the increase of time, from 0.075 at the initial state to 0.037 at the 11th day. The above results show that the decrease of fine particle content in soil samples during the test has a certain effect on the soil-water characteristic curve. In order to intuitively reflect this impact, the relation curve between the mass percentage of soil particles with size $d<0.02 \mathrm{~mm}$ and the residual volumetric water content is plotted in Figure 12.

Figure 12 manifests that the residual volumetric water content of the tested soil sample has a significant positive cor- relation with the mass percentage of fine particles. That is to say, with the migration and loss of fine particles in the permeability test, the mass percentage of fine particles and the residual volumetric water content both decrease gradually. The reason is that the specific surface area of soil particles is larger with higher fine particle content. A larger specific surface area corresponds to a stronger water adsorption capacity, resulting in higher residual volumetric water content. When the fine particle content decreases, the adsorption capacity is reduced and the residual volumetric water content diminishes accordingly.

3.4. Unsaturated Hydraulic Conductivity Results. Based on the determined saturated hydraulic conductivity and soilwater characteristic curve, the daily unsaturated hydraulic conductivity of the test soil sample was deduced by combining the Fredlund-Xing function model in the Geo-studio 


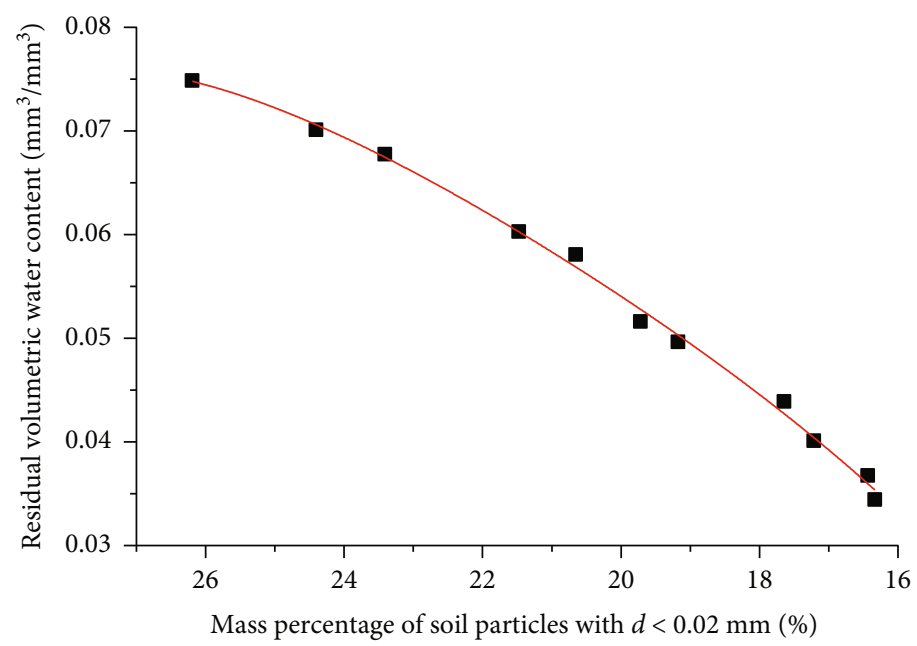

FIGURE 12: Relationship between mass percentage of particles $(d<0.02 \mathrm{~mm})$ and residual volumetric water content.

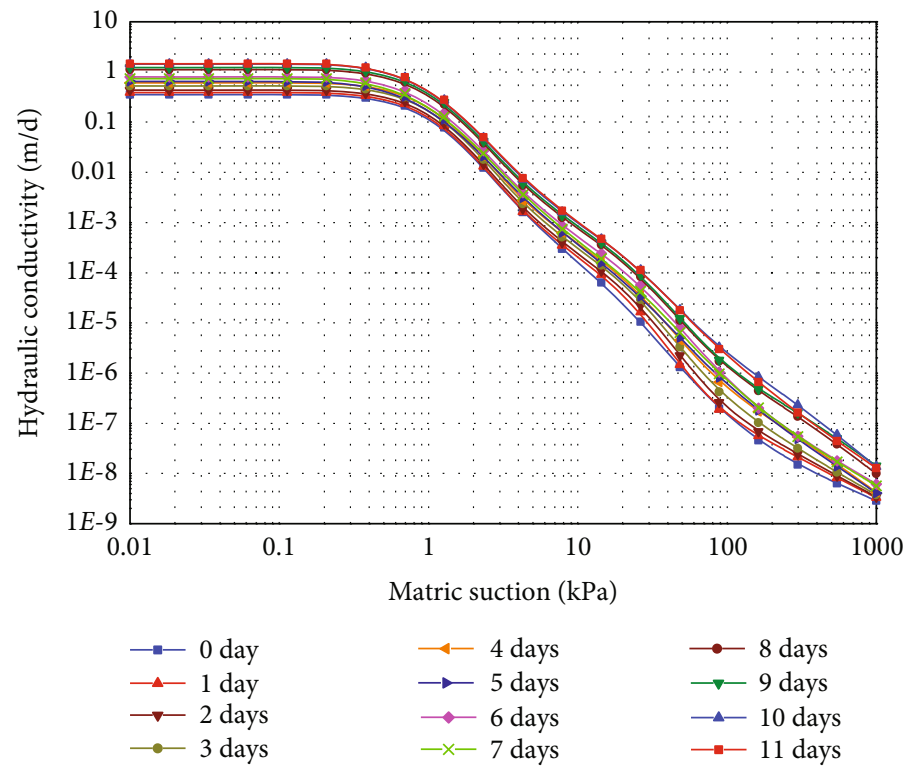

FIGURE 13: Unsaturated hydraulic conductivity functions of soil samples after different days of permeation.

software and shown in Figure 13. The variation trend of the unsaturated hydraulic conductivity function at different days is basically the same. It is basically unchanged at the initial stage when the matric suction is small. As the matric suction increases, the unsaturated hydraulic conductivity decreases gradually due to the diminution of the volumetric water content. Owing to the increase of porosity resulting from continuous migration and loss of fine particles in the soil during the test (Figure 10), the unsaturated hydraulic conductivity corresponding to a fixed matric suction increases with the decrease of reservoir water level (or increase of permeability test time). After 11 days of permeability test, the unsaturated hydraulic conductivity of the soil sample corresponding to a fixed matric suction between $30 \mathrm{kPa}$ and $300 \mathrm{kPa}$ even increases larger than 10 times that of the initial value.

\section{Influence of Hydraulic Parameter Variation on Slope Stability}

In order to study the influence of hydraulic parameter variation on slope stability, the slope stability of the Woshaxi landslide during reservoir water level drawdown was numerically simulated using the Morgenstern-Price limit equilibrium method by the Geo-studio software based on the tested hydraulic parameters presented in Section 3. In the Geostudio software, the slope stability analysis is performed in the Slope/W module, which can directly utilized the seepage results calculated in the Seep/W module. Figure 14 shows the simulated seepage field results of the Woshaxi landslide during water level falling at a velocity of $1.2 \mathrm{~m} / \mathrm{d}$ and the groundwater table in the slope generally decreasing with the time increasing. Based on the seepage calculation results acquired 


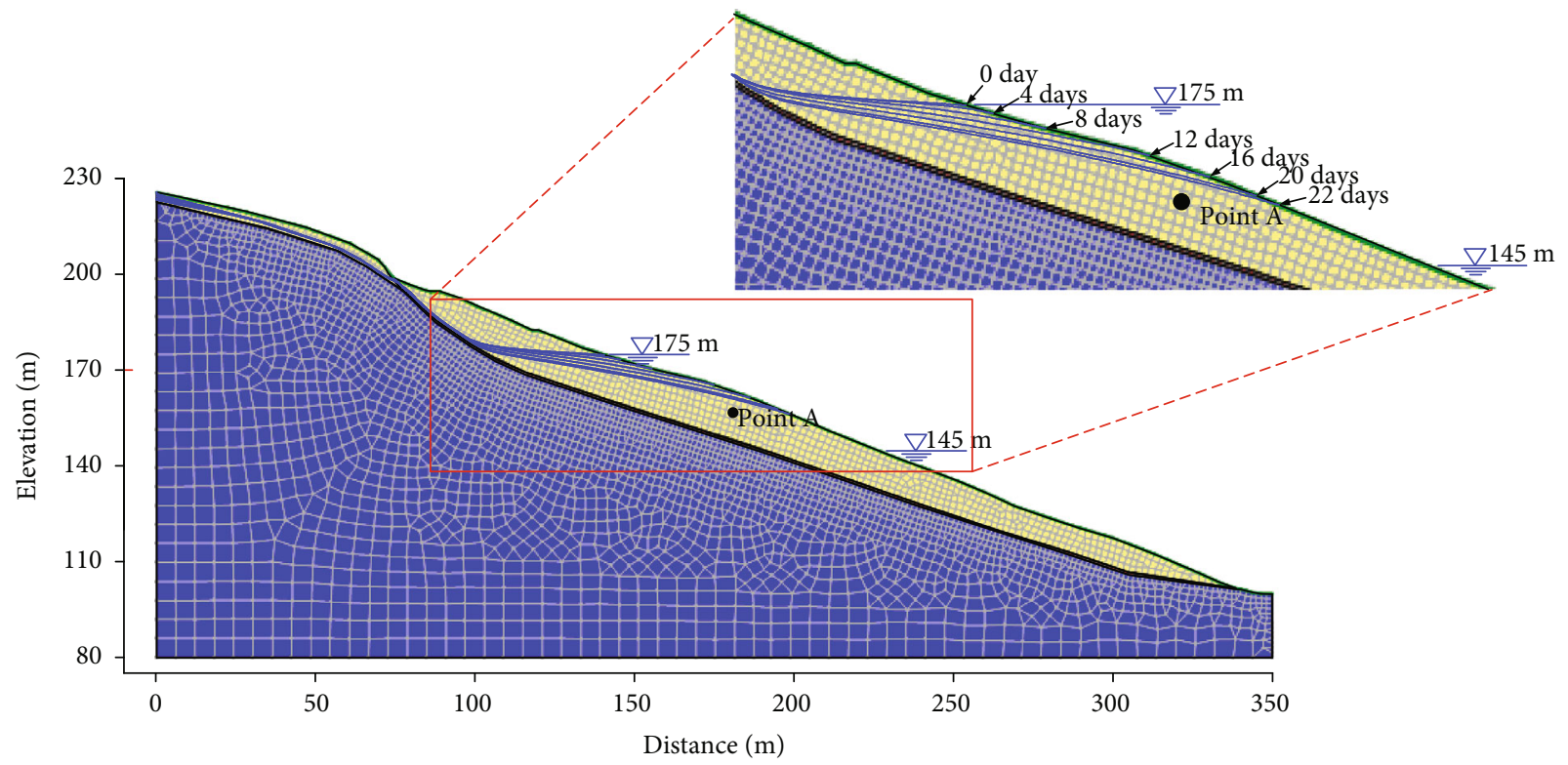

(a) With variational hydraulic parameters

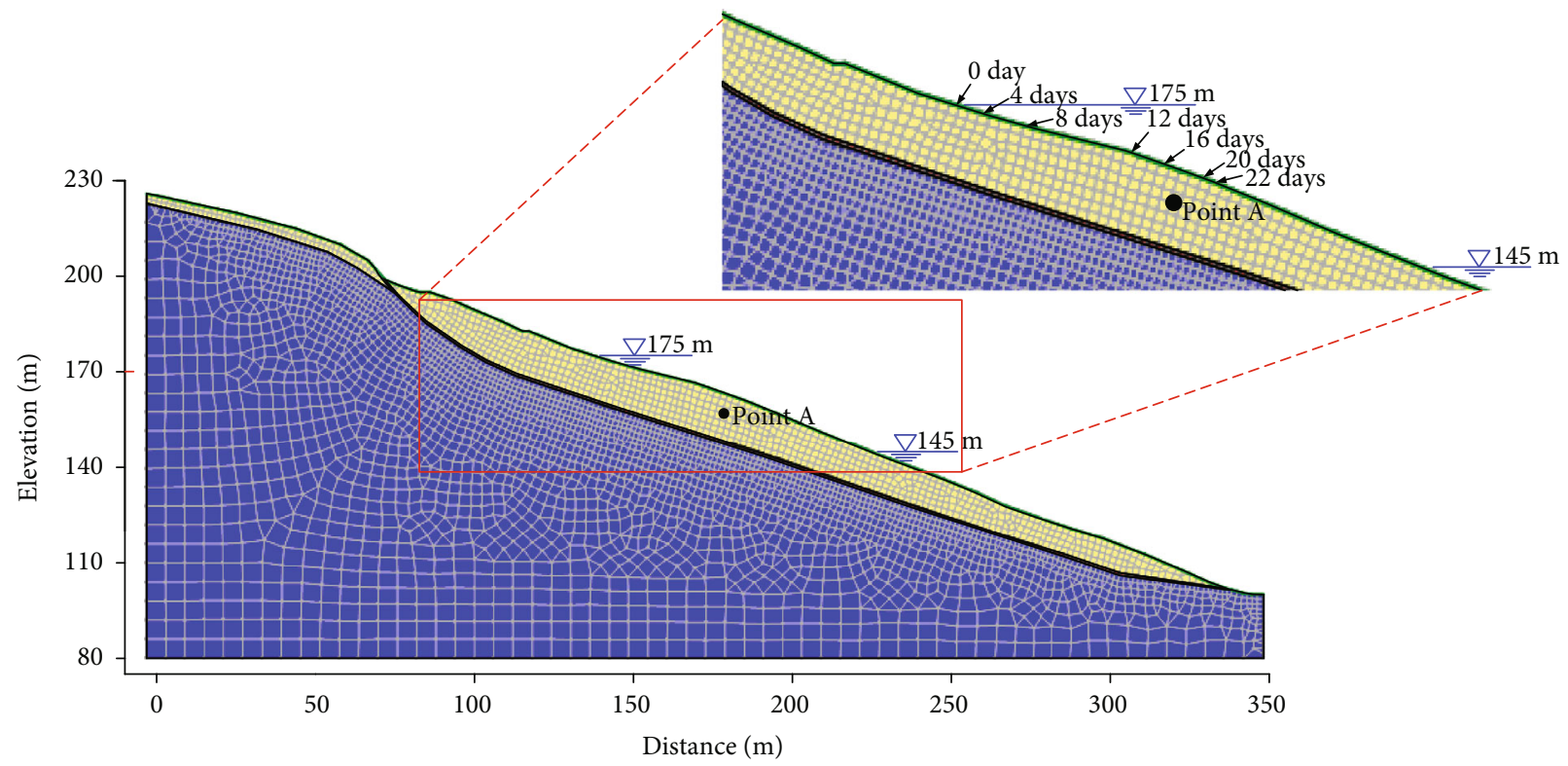

(b) With constant hydraulic parameters

FIgURE 14: Variation of groundwater tables during reservoir water level drawdown.

by the Seep/W module, the factors of safety of the Woshaxi landslide considering the variation of the soil-water characteristic curves and the unsaturated hydraulic conductivities during water level falling were calculated and shown in Figure 15. The shear strength parameters of the slip surface used in slope stability analysis were obtained from tests and engineering analogy, with a friction angle of $18^{\circ}$ and cohesion of $19 \mathrm{kPa}$. The calculated factor of safety gradually decreases with the drawdown of reservoir water level, demonstrating important influences of reservoir water falling on slope stability. When the water level falls below $159.4 \mathrm{~m}$, the factor of safety decreases less than 1.05 and the slope will much probably undergo a large deformation (normally, based on numerous field observations from lots of engineering experience [29], when the factor of safety of a soil slope is less than 1.05, the slope is most likely to have large deformations).

Also plotted in Figure 15 are the calculated factors of safety of the Woshaxi landslide with constant hydraulic parameters (initial soil-water characteristic curves and unsaturated hydraulic conductivities), which also show the change rule of continuous decrease with the decline of reservoir water level. However, the factors of safety with constant hydraulic parameters are generally larger than the results obtained with variational hydraulic parameters, and the difference is more obvious when the calculated factor of safety gets close to 1.05 (allowable critical value for engineering- 


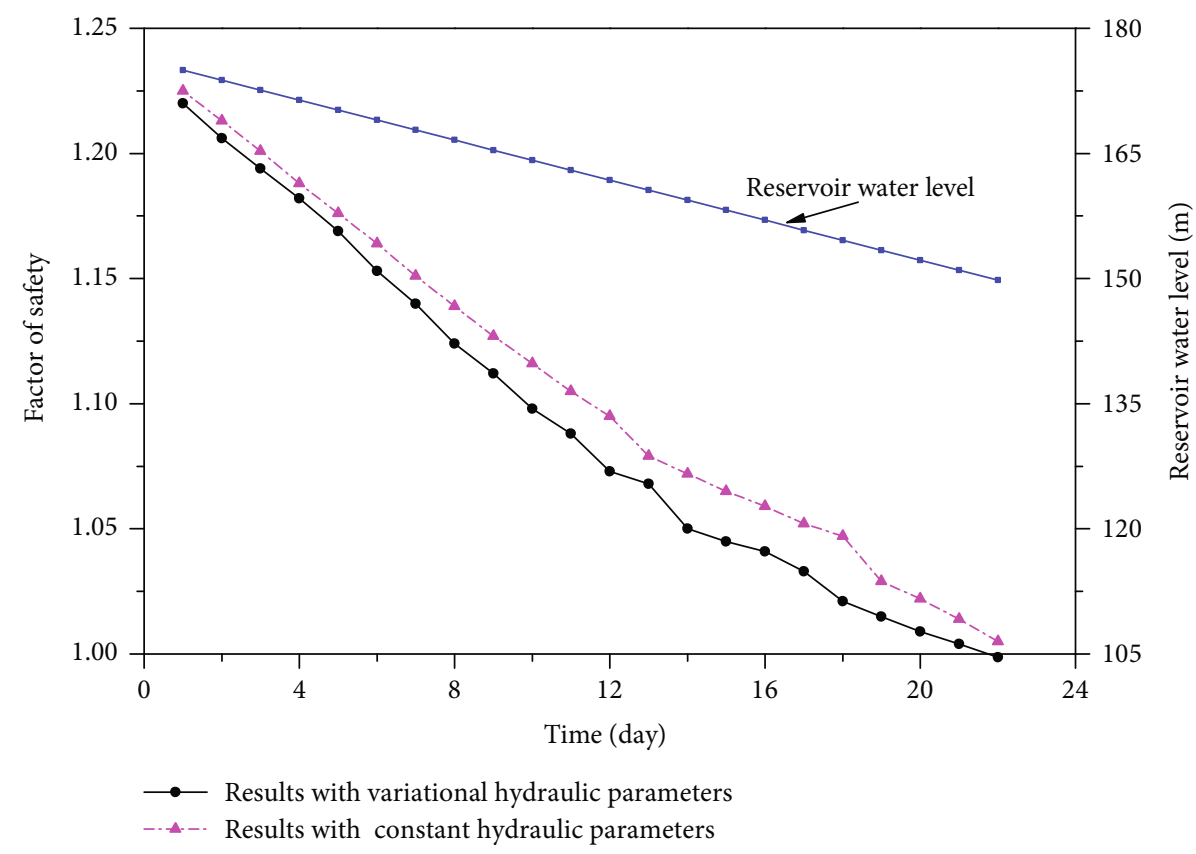

FIgURE 15: Changes in factors of safety of the slope during reservoir water level drawdown.

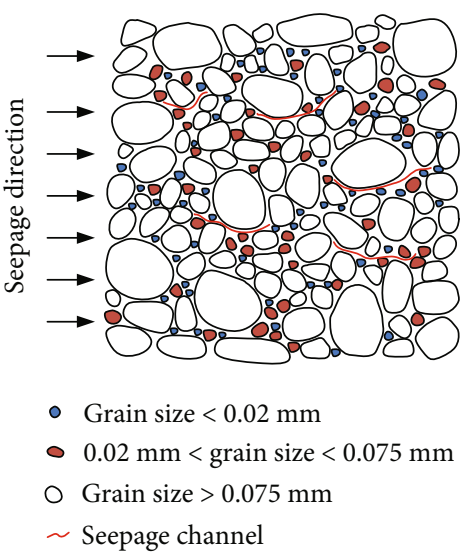

(a) Early stage

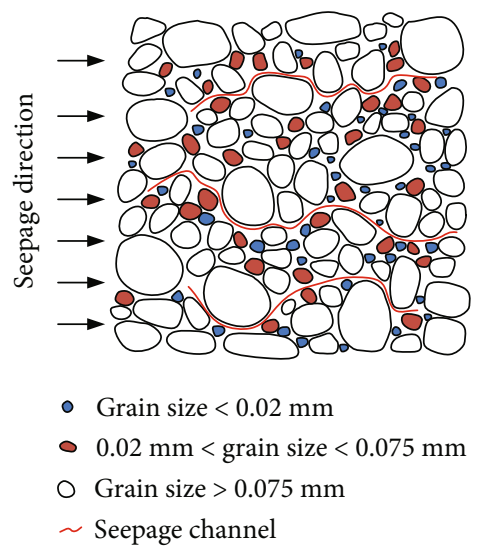

(b) Middle stage

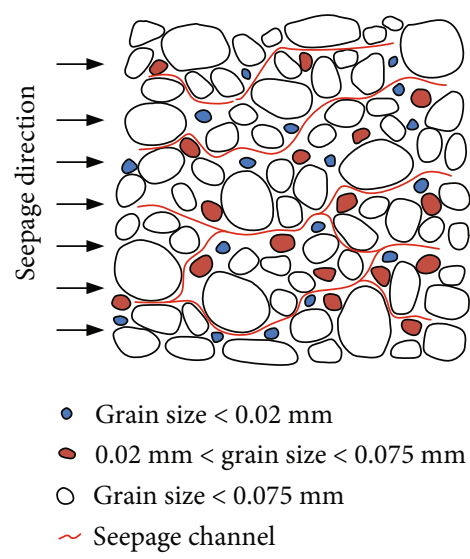

(c) Late stage

FIGURE 16: Schematic diagram of the soil seepage process.

safety requirement). Being close to the allowable value, even a small reduction of the factor of safety can result in a big deformation of the reservoir bank slope in practice. Obviously, it is dangerous to ignore the dynamic change of hydraulic parameters during reservoir water level drawdown when calculating the factor of safety of a soil slope; the slope safety and deformation degree may be misjudged based on the results obtained with constant hydraulic parameters. Therefore, the influence of the dynamic change of hydraulic parameters on slope stability evaluation during reservoir water level drawdown should be accounted in engineering practice. In addition, it should be mentioned that the mechanical parameters may also exhibit dynamic characteristics during this process and play an important effect on slope stability, which is not considered in this paper and will be studied in the future.

\section{Discussion}

Based on the aforementioned test results and analysis, the permeability characteristics of the unsaturated soil in the Woshaxi landslide during the reservoir water drawdown process are discussed. The sliding soil mass of the Woshaxi landslide is classified as a coarse soil, with fine particles filling in the pores formed by coarse particles that serve as the skeleton. The seepage process of the unsaturated soil during reservoir water level falling is shown in Figure 16. In the early permeation stage, the content of fine particles in the soil is high, which results in a large specific surface area of the soil particles, a strong water-holding capacity of the soil, a small pore space formed in the soil, and a less developed seepage channel (see Figures 10 and 16(a)). Therefore, the initial saturated hydraulic conductivity of the soil mass is relatively 
small. With the decrease of the reservoir water level, the fine particles in the soil migrated and were lost because of the seepage force generated by water flow. As a result, the pore space increases and more obvious seepage channels develop (see Figures 10 and 16(b)), which causes the increase in soil saturated hydraulic conductivity. Meanwhile, the volumetric water content of the soil under a high matric suction condition decreases gradually owing to the reduction of the specific surface area and water adsorption capacity triggered by the loss of fine particles. In the later permeation stage, most fine particles in the pore structure are rushed out under the seepage force action and the seepage channels gradually develop and become interconnected (see Figures 10 and 16(c)). At this time, the increase rate of saturated hydraulic conductivity decreases, and changes of volumetric water content and unsaturated hydraulic conductivity of the tested samples at the same matric suction condition tend to be smaller with an increase of permeation time.

\section{Conclusions}

In this paper, seepage tests considering the dynamic change of water head and seepage direction caused by reservoir water level decrease were carried out by using an independently developed permeation apparatus, which can simulate the seepage process of soils inside the bank slope in the reservoir area. The dynamic variation characteristics of particle size distributions, soil-water characteristic curves, and unsaturated hydraulic conductivities under a reservoir water drawdown condition were studied by combining the physical empirical model and numerical simulation during the permeability test. The research conclusions are as follows:

(1) Compared with the conventional infiltration instrument, the developed permeation apparatus in this paper can truly and effectively simulate the change of the seepage field of the soil inside the bank slope during reservoir water rising and falling processes by adjusting the prescribed water head value and inclination angle of the sample in real time. It can provide technical support for the determination of unsaturated permeability characteristics of the soil in the bank slope during reservoir operation

(2) In the simulated reservoir water level falling process, the fine particles in the soil of the sliding mass migrated and were lost under the seepage force action. The grain-size distribution curve changed obviously in the fine grain segment, in which the decrease of particles with a size less than $0.02 \mathrm{~mm}$ dominated. According to the developing process of the seepage channels in the soil sample, the saturated hydraulic conductivity showed a gradually increasing trend during the test, with the change rate increasing at first and then decreasing

(3) During the permeability test, the soil-water characteristic curve changes slightly in the low matric suction segment $(0.1 \sim 10 \mathrm{kPa})$, but there were obvious changes in the high matric suction segment $\left(10 \sim 10^{4} \mathrm{kPa}\right)$. Under high matric suction, the volumetric water content positively correlated with the fine particle content decreased with the increase of permeation time (or the decrease of reservoir water level). With the decrease of reservoir water level, the unsaturated hydraulic conductivity of the soil sample corresponding to a fixed matric suction increases

(4) Compared with the results obtained considering the dynamic change of hydraulic parameters during reservoir water level drawdown, the calculated factor of safety with constant hydraulic parameters is generally larger and dangerous for landslide safety evaluation, demonstrating the importance of accounting for the influence of the dynamic change of hydraulic parameters on slope stability evaluation during reservoir water level drawdown in practice

\section{Data Availability}

All data, models, and code generated or used during the study appear in the article, and the authors are not restricted from sharing their data and materials.

\section{Conflicts of Interest}

The authors declare that they have no conflicts of interest.

\section{Acknowledgments}

The research was funded by financial support from the National Natural Science Foundation of China (Grant Nos. 51579063 and 51709072), the Anhui Provincial Natural Science Foundation (Grant No. 1808085QE145), the Open Research Fund of Key Laboratory of Geological Hazards on Three Gorges Reservoir Area (China Three Gorges University), Ministry of Education (2018KDZ07), and the China Scholar Council (Grant Nos. 201806695005 and 201906695025).

\section{References}

[1] X. Luo, F. Wang, Z. Zhang, and A. Che, "Establishing a monitoring network for an impoundment-induced landslide in Three Gorges Reservoir Area, China," Landslides, vol. 6, no. 1, pp. 27-37, 2009.

[2] F. Wang, Y. Zhang, Z. Huo, X. Peng, K. Araiba, and G. Wang, "Movement of the Shuping landslide in the first four years after the initial impoundment of the Three Gorges Dam Reservoir, China," Landslides, vol. 5, no. 3, pp. 321-329, 2008.

[3] S. Li, Q. Sun, Z. Zhang, and X. Luo, "Physical modelling and numerical analysis of slope instability subjected to reservoir impoundment of the Three Gorges," Environmental Earth Sciences, vol. 77, no. 4, p. 138, 2018.

[4] G. W. Jia, T. L. T. Zhan, Y. M. Chen, and D. G. Fredlund, "Performance of a large-scale slope model subjected to rising and lowering water levels," Engineering Geology, vol. 106, no. 1-2, pp. 92-103, 2009.

[5] P. Paronuzzi, E. Rigo, and A. Bolla, "Influence of fillingdrawdown cycles of the Vajont reservoir on Mt. Toc slope stability," Geomorphology, vol. 191, pp. 75-93, 2013. 
[6] M. W. Gui and Y. M. Wu, "Failure of soil under water infiltration condition," Engineering Geology, vol. 181, pp. 124-141, 2014.

[7] L. Xiang, S. Wang, and L. Wang, "Response of typical hydrodynamic pressure landslide to reservoir water level fluctuation: Shuping landslide in Three Gorges Reservoir as an example," Journal of Engineering Geology, vol. 22, no. 5, pp. 876-882, 2014.

[8] S. Cuomo and S. Della Sala, "Rainfall-induced infiltration, runoff and failure in steep unsaturated shallow soil deposits," Engineering Geology, vol. 162, pp. 118-127, 2013.

[9] D. G. Fredlund and H. Rahardjo, Soil mechanics for unsaturated soils, John Wiley \& Sons, Inc., 1993.

[10] K. Song, E. Yan, G. Zhang, S. Lu, and Q. Yi, "Effect of hydraulic properties of soil and fluctuation velocity of reservoir water on landslide stability," Environmental Earth Sciences, vol. 74, no. 6, pp. 5319-5329, 2015.

[11] Y. R. Zheng and X. S. Tang, "Stability analysis of slopes under drawdown condition of reservoirs," Chinese Journal of Geotechnical Engineering, vol. 29, no. 8, pp. 1115-1121, 2007.

[12] W. X. Jian, Q. Xu, H. Wu, and L. Y. Tong, "Study of unsaturated hydraulic parameters of Huangtupo landslide in Three Gorges Reservoir Area," Rock and Soil Mechanics, vol. 35, no. 12, pp. 3517-3522, 2014.

[13] J. Wei, J. Deng, G. Tan, L. G. Tham, and C. F. Lee, "Field tests of saturated and unsaturated hydraulic parameters of gravelly soil in Xietan landslide," Rock and Soil Mechanics, vol. 28, no. 2, pp. 327-330, 2007.

[14] A. Wayllace and N. Lu, "A transient water release and imbibitions method for rapidly measuring wetting and drying soil water retention and hydraulic conductivity functions," Geotechnical Testing Journal, vol. 35, no. 1, article 103596, 2012.

[15] C. Zuo, D. Liu, S. Ding, X. Tang, and Z. Yuan, "Prediction and evaluation on soil water retention curve of landslide soil based on fractal of particles," Science Technology and Engineering, vol. 14, no. 32, pp. 276-281, 2014.

[16] G. Crosta and C. di Prisco, "On slope instability induced by seepage erosion," Canadian Geotechnical Journal, vol. 36, no. 6, pp. 1056-1073, 1999.

[17] S. R. Hencher, "Preferential flow paths through soil and rock and their association with landslides," Hydrological Processes, vol. 24, no. 12, pp. 1610-1630, 2010.

[18] Y. Lu, G. Chen, X. Luo, and Y. Cui, "Study of soil-water characteristical curve and its influential factors," Rock and Soil Mechanics, vol. 29, no. 8, pp. 2481-2486, 2008.

[19] B. Wen and Y. Hu, "Effect of particle size distribution on the metric suction of unsaturated clayey soils," Hydrogeology \& Engineering Geology, vol. 35, no. 6, pp. 50-54, 2008.

[20] SL 237-1999, Specification of Soil Test, Water Power Press, China, 1999.

[21] Y. Kong and E. Song, "A method for estimating soil-water characteristic curve from grain-size distribution," Rock and Soil Mechanics, vol. 36, no. 9, pp. 2487-2493, 2015.

[22] R. Hu, Y. F. Chen, H. H. Liu, and C. B. Zhou, "A water retention curve and unsaturated hydraulic conductivity model for deformable soils: consideration of the change in pore-size distribution," Géotechnique, vol. 63, no. 16, pp. 1389-1405, 2013.

[23] A. G. Hunt, B. Ghanbarian, and K. C. Saville, "Unsaturated hydraulic conductivity modeling for porous media with two fractal regimes," Geoderma, vol. 207-208, pp. 268-278, 2013.
[24] Q. Zhai and H. Rahardjo, "Estimation of permeability function from the soil-water characteristic curve," Engineering Geology, vol. 199, pp. 148-156, 2015.

[25] T. Wen, L. Shao, and X. Guo, "Permeability function for unsaturated soil," European Journal of Environmental and Civil Engineering, pp. 1-13, 2018.

[26] D. G. Fredlund, A. Xing, and S. Huang, "Predicting the permeability function for unsaturated soils using the soil-water characteristic curve," Canadian Geotechnical Journal, vol. 31, no. 4, pp. 533-546, 1994.

[27] M. T. van Genuchten, "A closed-form equation for predicting the hydraulic conductivity of unsaturated Soils1," Soil Science Society of America Journal, vol. 44, no. 5, pp. 892-898, 1980.

[28] J. Liu and X. Zhang, "Study on filter design of broadly-graded soil," Chinese Journal of Geotechnical Engineering, vol. 18, no. 6, pp. 1-9, 1996.

[29] Three Gorges Reservoir Geological Disaster Prevention and Control Headquarters, Specification for design of geological disaster prevention and control project in the Three Gorges Reservoir Area, China University of Geosciences Press, Wuhan, China, 2014.

[30] G. Zhang, Researches on meso-scale mechanism of piping failure by means of model test and PFC numerical simulation, Tongji University, China, 2007. 

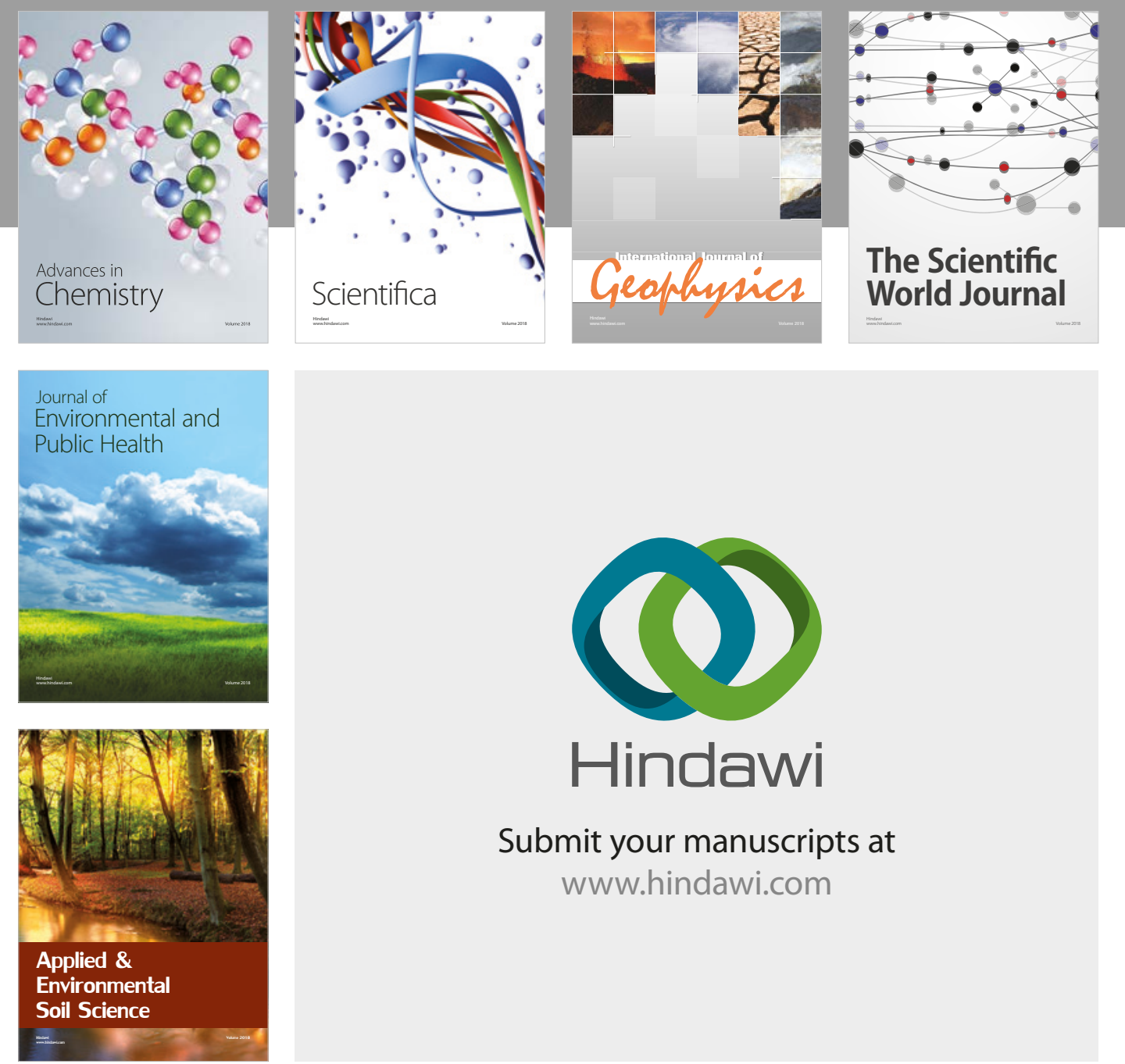

The Scientific

\section{World Journal}
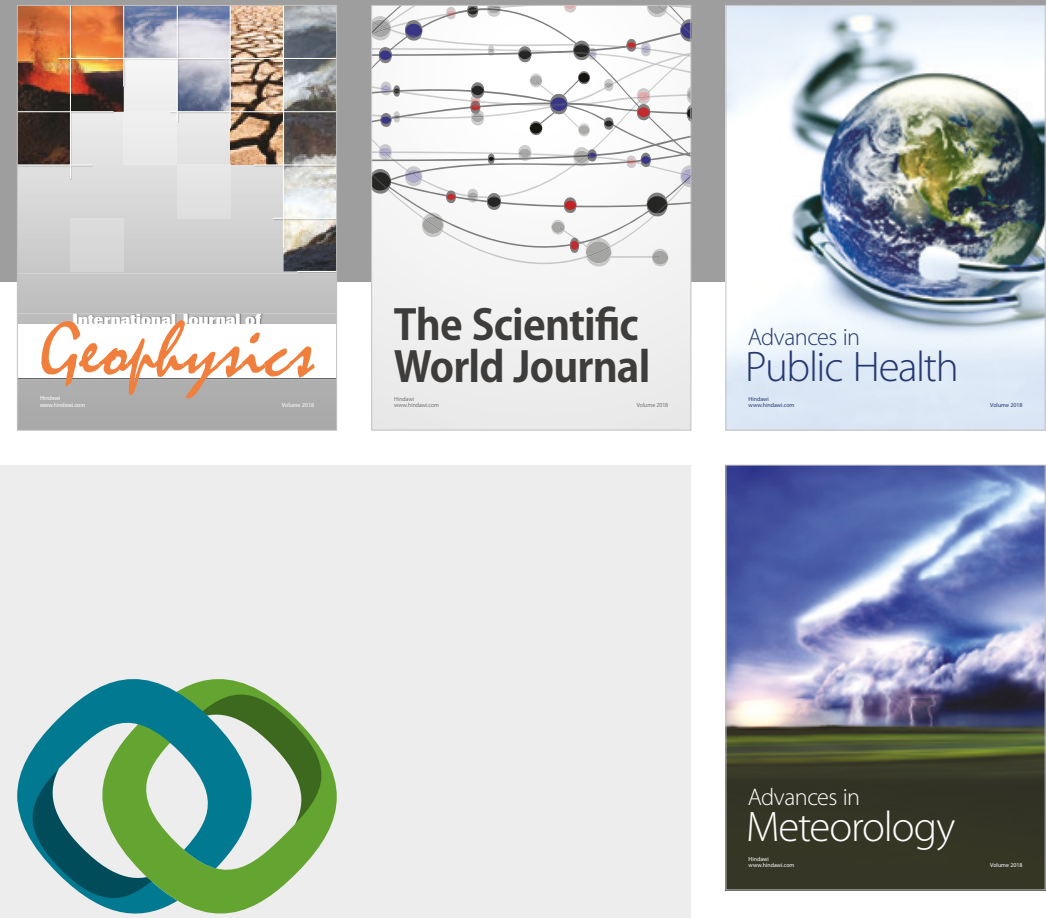

Advan

Public Health

\section{Hindawi}

Submit your manuscripts at

www.hindawi.com
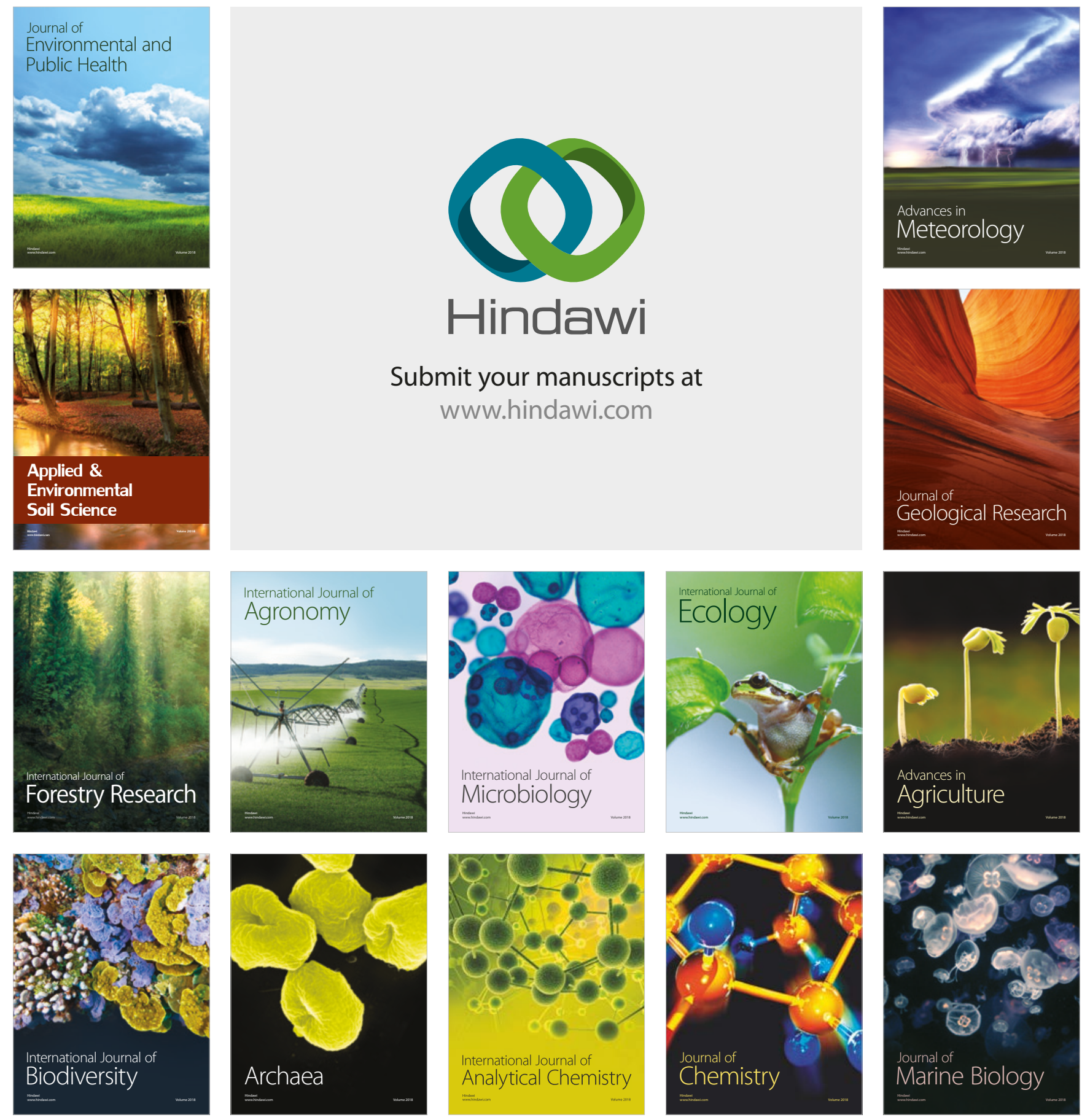